\title{
A REFORMA DO ENSINO MÉDIO NAS TRILHAS NEOLIBERAIS
}

\author{
The High School Reform on the Neoliberalism Path
}

\author{
Daniele de Oliveira Moreira BARBOSA \\ Mestranda pela Universidade Federal de Mato Grosso do Sul (Bolsista CAPES) \\ danieleo.moreira.barbosa@gmail.com \\ https://orcid.org/0000-0001-9528-1631
}

Daniela Sayuri Kawamoto KANASHIRO
Universidade Federal de Mato Grosso do Sul
daniela.kanashiro@ ufms.br
https://orcid.org/0000-0001-5017-1420

RESUMO: Neste trabalho, temos por objetivo analisar algumas regulamentações estabelecidas na Reforma do Ensino Médio que foi inicialmente proposta pela Medida Provisória (MP) $\mathrm{n}^{\circ} 746$ (BRASIL, 2016a), posteriormente regulamentada pela Lei $n^{\circ} 13.415$ (BRASIL, 2017) e sancionada, na época, pelo então presidente Michel Temer. Há proposições que alteram a Lei de Diretrizes e Bases (LDB) $n^{\circ} 9.394$ (BRASIL, 1996), tais como a inserção dos itinerários formativos e questões relativas ao notório saber. A metodologia de pesquisa utilizada é de revisão bibliográfica e de análise documental. À luz de teóricos que discutem o contexto neoliberal (LUDWIG, 2000; NASCIMENTO, 2018), a formação docente (MONTE MÓR, 2015; SZUNDY, 2019, TARDIF, 2014) e a educação linguística (RAJAGOPALAN, 2003; SOUZA, 2019) problematizamos a Reforma do Ensino Médio e seus impactos nos anos finais da educação básica.

PALAVRAS-CHAVE: Neoliberalismo; Notório saber; Itinerários formativos.

\begin{abstract}
This piece of work has the objective of analyzing some policies defined in The High School Reform, which was initially proposed by the Provisional Measure $\mathrm{n}^{\circ} 746$ (BRASIL, 2016). It was later regulated by Law 13,415 (BRASIL, 2017) and sanctioned, at the time, by president Michel Temer. There are propositions that modify the Brazilian Law of Education (Lei de Diretrizes e Bases - LDB) 9.394 (BRASIL, 1996) such as the inclusion of elective tracks and questions related to hiring a teacher that does not have a degree, but shows undisputed knowledge in the area, which has been defined as "notório saber". The research methodology used is bibliographic review and document analysis. In the light of theorists who discuss the neoliberal context (LUDWIG, 2000; NASCIMENTO, 2018), the teacher education (MONTE MÓR, 2015; SZUNDY, 2019; TARDIF, 2014) and the
\end{abstract}


linguistic education (RAJAGOPALAN, 2003; SOUZA, 2019), we discuss the High School Reform and its impacts on final years of basic education.

KEYWORDS: Neoliberalism; Notorious knowledge; Training itineraries.

\section{INTRODUÇÃO}

O presente estudo objetiva discutir algumas regulamentações estabelecidas na Lei $n^{\circ} 13.415$ (BRASIL, 2017), imposta pela Medida Provisória (MP) no 746 (BRASIL, 2016a), instituída pelo governo de Michel Temer. Diferentemente de um projeto de lei que, antes de ser regulamentado, passa por ampla discussão no âmbito legislativo, a MP é um ato determinado pelo presidente da República, justificado pela urgência e relevância cumulativamente. Embora a MP seja um ato legal, garantido no artigo 62 da Emenda Constitucional $n^{\circ} 32$ (BRASIL, 2001), é preciso evidenciar que se trata de um ato unipessoal, autoritário e impositivo.

A referida Lei $n^{\circ} 13.415 / 2017$ alterou as Leis $n^{\circ} 9.394$ (BRASIL, 1996), que estabeleceu as Diretrizes e Bases da Educação Nacional e n 11.494 (BRASIL, 2007), que regulamentou o Fundo de Manutenção e Desenvolvimento da Educação Básica e de Valorização dos Profissionais da Educação, bem como a Consolidação das Leis do Trabalho - CLT; revogou a Lei $n^{\circ} 11.161$ (BRASIL, 2005), que dispunha sobre a língua espanhola na educação básica; e instituiu a Política de Fomento à Implementação de Escolas de Ensino Médio em Tempo Integral.

A justificativa para tais mudanças reside em dados negativos, no âmbito da educação, tais como a evasão e o abandono no ensino médio e os baixos resultados educacionais demonstrados em provas em larga escala como a do Sistema de Avaliação da Educação Básica (Saeb) para essa etapa. A exposição de vários outros motivos foi publicada em 15 de setembro de 2016, pelo então ministro da Educação, José Mendonça Bezerra Filho. A íntegra dos motivos, assinada pelo ministro para apresentação ao presidente da república, aparece correlacionada à MP $n^{\circ} 746 / 2016$, no início do documento on-line, no link "Exposição de motivos".

\footnotetext{
${ }^{1}$ Disponível em: <http://www.planalto.gov.br/ccivil_03/_Ato2015-2018/2016/Exm/Exm-MP-746-16.pdf>. Acesso em: 3 mar. 2020.
} 
Neste artigo, analisamos duas regulamentações da Lei $n^{\circ}$ 13.415/2017, quais sejam, os itinerários formativos e o notório saber. Ambas impactam a formação do aluno e a profissão docente e, neste trabalho, vamos discutir alguns aspectos relacionados às línguas adicionais. Para tanto, recorremos também ao estudo da Resolução $\mathrm{n}^{\mathrm{o}}$ 3, de 21 de novembro de 2018 (BRASIL, 2018a), que atualiza as Diretrizes Curriculares Nacionais para o Ensino Médio (DCNEM) e explicita como os itinerários formativos serão desenvolvidos e o notório saber será implantado.

A primeira alteração apresenta cinco itinerários formativos, que serão oferecidos para os alunos do ensino médio conforme a relevância para o contexto local e a possibilidade dos sistemas de ensino, sendo eles: I - linguagens e suas tecnologias; II matemática e suas tecnologias; III - ciências da natureza e suas tecnologias; IV - ciências humanas e sociais aplicadas; V - formação técnica e profissional. Isso quer dizer que o estudante pode desejar optar por um itinerário, mas este não ser ofertado na escola por falta de docentes de determinadas disciplinas ou área, por exemplo. Além de outros efeitos, a alteração tende a "resolver" a falta de professores, já que a instituição de ensino não tem, segundo a mencionada lei, de se responsabilizar por oferecer todos os percursos, mesmo que essa prerrogativa interfira na liberdade de escolha do aluno.

A segunda mudança indicada desvaloriza o processo de formação docente, pois autoriza que profissionais que não são graduados em cursos de licenciatura e, portanto, não são habilitados para lecionarem, possam ministrar aulas no ensino médio, especificamente no itinerário $\mathrm{V}$, referente à formação técnica e profissional. Ainda que essa alteração esteja restrita ao ensino técnico, concordamos com pesquisadores como Oliveira, Oliveira e Araújo (2017) que indicam que tal medida pode abrir precedentes para que outros itinerários façam uso da mesma manobra e contribuam para o enfraquecimento da profissionalização da docência.

Também julgamos relevante mencionar que a Lei $n^{\circ}$ 9.394/1996 assinalava que a comunidade escolar tinha a liberdade de escolher a língua adicional a ser ensinada na escola, conforme os fatores históricos, os relativos às comunidades locais e à tradição, explicitados nos Parâmetros Curriculares Nacionais (PCN) - língua estrangeira (BRASIL, 1998). Na contramão da possibilidade de escolha do idioma a ser desenvolvido, a Reforma instituiu a oferta obrigatória do inglês e estabeleceu que a escola poderá ofertar 
outro idioma em caráter optativo, preferencialmente, o espanhol.

Justificamos o desenvolvimento desta pesquisa, tendo em vista os impactos que essas regulamentações podem provocar no contexto educacional, particularmente no âmbito da educação linguística, na oferta dos idiomas e na atuação docente de línguas adicionais. Além disso, consideramos importante destacar que, em virtude das recentes mudanças, os estudos sobre o tema são ainda incipientes e demandam, portanto, a necessidade de ampliar e aprofundar discussões e pesquisas.

Para analisar os itinerários formativos e o notório saber, pautamo-nos em teorias neoliberais que subjazem nas regulamentações da Reforma do Ensino Médio, tendo como referências Ludwig (2000) e Nascimento (2018), por exemplo; sobre formação docente, especialmente, Monte Mór (2015), Tardif (2014) e Szundy (2019); e acerca da educação linguística, Rajagopalan (2003, 2019) e Souza (2019). A metodologia de pesquisa utilizada é de revisão bibliográfica e de análise documental com natureza qualitativa e características interpretativistas. Problematizamos os impactos da Reforma, discutimos também as mudanças referentes à oferta de línguas estrangeiras e à formação de professores. Avaliamos como fundamental o engajamento da comunidade acadêmica na discussão dos documentos oficiais que afetam a educação básica, a política linguística e a profissionalização docente.

Organizamos o artigo da seguinte forma: na seção a seguir, temos o alicerce teórico desta pesquisa e nele tratamos acerca da influência das políticas neoliberais no âmbito educacional. Depois, prosseguimos com a análise de dados, abordamos a Reforma do Ensino Médio, discutindo especificamente os itinerários formativos e o notório saber. Por último, encerramos com as considerações finais e apresentamos as referências.

\section{O NEOLIBERALISMO E A EDUCAÇÃO}

Conforme Andrade (2019), o conceito de neoliberalismo é polêmico e, depois das reformas no Chile, no final da década de 70 do século passado, no governo Pinochet, foi definido como processo de "desregulamentação dos mercados, de privatização e de desmonte do Estado de bem-estar ao redor do mundo" (ANDRADE, 2019, p. 212). Dentre outros teóricos que também o conceituam, citamos a definição proposta por Harvey (2005) 
Uma teoria da política econômica que propõe que o bem-estar humano pode ser melhor promovido permitindo a liberdade individual, o empreendedorismo e habilidades dentro de uma estrutura institucional caracterizado por fortes direitos de propriedade privada e livre mercado. ${ }^{2}$

(HARVEY, 2005, p. 2).

Nascimento (2018) caracteriza o neoliberalismo asseverando que pode ser compreendido como uma forma radicalizada de capitalismo, isto é, uma reconfiguração contemporânea ou global do capitalismo, que vai além da questão econômica, "associando-se a uma racionalidade política que se impõe por meio de uma racionalidade mercadológica em outras esferas da vida por intermédio de uma organização social e governamental" (NASCIMENTO, 2018, p. 43). Conforme Flubacher e Percio (2017 $7^{3}$ apud SZUNDY, 2019, p. 123) "o neoliberalismo, tendo como principal mote a liberdade e a competição, transforma as relações entre o estado, o capital, a propriedade e o indivíduo ao estender os valores do mercado à (sic) todas instituições e (inter)ações sociais". Assim, por estimular o individualismo, a meritocracia, a disputa entre as pessoas, as relações sociais também são reduzidas às práticas mercadológicas. Os neoliberais defendem as privatizações das empresas estatais, considerando que "as atividades estatais passam a ser encaradas como algo improdutivo, não eficiente e anti-econômico (sic)" (LUDWIG, 2000, p. 41). Desse modo, o que era oferecido pelo Estado, deve ser comprado no mercado.

No Brasil, Nascimento (2018, p. 42) entende que "o neoliberalismo parece ser fortemente marcado pelo colonialismo, em várias esferas, inclusive na educação, em especial na área da linguística". Jordão (2008) esclarece que o colonialismo no âmbito educacional, é estabelecido quando as nações "avançadas", "desenvolvidas" ou "países do primeiro mundo" têm influência significativa sobre outras nações, principalmente no que diz respeito ao conhecimento, à cultura e à educação.

\footnotetext{
${ }^{2}$ Todas as citações em língua estrangeira são traduções livres nossas. No original: "a theory of political economic practices that proposes that human well-being can best be advanced by liberating individual entrepreneurial freedoms and skills within an institutional framework characterized by Strong private property rights, freemarkets, and free trade".

3 PERCIO, A.; FLUBACHER, M.. Language, education and neoliberalism. In: FLUBACHER, M.; PERCIO, A. Language, education and Neoliberalism. Critical Studies in Sociolinguistics. Bristol, UK: Multilingual Matters, 2017. Chapter 1. Kindle Edition.
} 
Nascimento (2018, p. 42), baseada em Stiegler ${ }^{4}$ (2015), acrescenta que o neoliberalismo é "caracterizado essencialmente por individualismo e competitividade" e nele ocorre

\begin{abstract}
a ênfase no indivíduo em contraposição à coletividade e crença de que a reconfiguração do papel do estado, com vistas a promover a auto regulação do mercado, seja um caminho para viabilizar o crescimento econômico. Tais características parecem adentrar as instituições educativas, as quais cada vez mais passam a ser avaliadas, e seus estudantes classificados, conforme seus desempenhos individuais. Recai, portanto, "a culpa" de uma "má" educação sobre alunos, e, por conseguinte, professores, recorrendo à culpabilização do indivíduo pelo seu sucesso ou fracasso. (NASCIMENTO, 2018, p. 44).
\end{abstract}

Vemos assim que, ao trazer princípios do neoliberalismo para o âmbito da educação, são aplicadas experiências do setor econômico e ocorre a busca por resultados e metas. Essa "responsabilização" que se baseia em resultados de testes em larga escala, segundo Rodgers (2008, p. 39), pressupõe que "Ensinar é uma atividade técnica, o conhecimento é estático, a boa prática é universal, estar preparado para lecionar é conhecer a matéria, o aprendizado do aluno é igual à pontuação alta em testes de elevado grau de dificuldade".

Entre as variadas consequências que surgem ao se abraçar as políticas neoliberais, destacamos algumas ações: (a) a não valorização e o desprezo pela profissão de professor; (b) a permissão de profissionais sem licenciatura a atuarem na educação básica; (c) a padronização nacional do ensino; (d) a fragmentação do currículo por eixos temáticos (NASCIMENTO, 2018; SZUNDY, 2019). Isso posto, observamos que o caminho escolhido pelos neoliberais, para a "formação" docente é utilizar da "velha fórmula de treinar e controlar o desempenho do professor", valorizando somente ações práticas "que levem a resultados concretos, com um claro sentido de treinamento, privilegiando, no processo pedagógico, o como fazer" (BONFANTE; BETT; BITTENCOURT, 2018, p. 83). Desse modo, para Medeiros e Pires (2014), a formação de professores da educação básica, no cenário político atual, tem a finalidade de alienar, produzir, reproduzir e manter o capitalismo, ou seja, está direcionada apenas para o crescimento econômico e

\footnotetext{
${ }^{4}$ STIEGLER, Bernard. States of Shock: Stupidity and Knowledge in the 21 st Century. Trans. Daniel Ross. Cambridge, UK: Polity Press, 2015.
} 
desenvolvimento social do país e, como mencionou Rodgers (2008, p. 39), "gerar trabalhadores produtivos e competir com sucesso na economia global”.

$\mathrm{Na}$ contramão das perspectivas neoliberais, em tempos de complexidade da realidade e de especificidades locais, em oposição ao engessamento do conteúdo, da preparação para as provas e, consequentemente, da competitividade, Souza (2019, p. 303) defende a importância de "Preparar o professor protagonista, um professor que é capaz de analisar quem é seu aluno, o seu contexto de ensino, quais são as necessidades do seu contexto, desses alunos, quais são os recursos disponíveis e, a partir disso, o que ele pode fazer". Dessa forma, ser professor implica muito mais que saber determinado conteúdo ou ser treinado para usar determinada metodologia. Igualmente, Tardif (2014) afirma que

um professor de profissão não é somente alguém que aplica conhecimentos produzidos por outros, não é somente um agente determinado por mecanismos sociais: é um ator no sentido forte do termo, isto é, um sujeito que assume sua prática a partir dos significados que ele mesmo lhe dá, um sujeito que possui conhecimentos e um saberfazer provenientes de sua própria atividade e a partir dos quais ele a estrutura e a orienta. (TARDIF, 2014, p. 230).

Tardif (2014) acrescenta também que "o professor é alguém que deve: 1. conhecer sua matéria, sua disciplina, seu programa; 2. possuir conhecimentos relativos às ciências da educação e à pedagogia; 3. desenvolver um saber prático baseado em sua experiência cotidiana com os alunos" (TARDIF, 2014, p. 39), ou seja, há saberes estabelecidos para o exercício do professorado, muito além do conhecimento do conteúdo. Monte Mór (2015) defende o pluralismo na educação: "Trata-se de uma profissionalização que agrega o conhecimento técnico com a sensibilização, a percepção para o contexto, o entorno, as diferenças, as ressignificações, as mudanças" (MONTE MÓR, 2015, p. 39). No caso da formação docente, também assinala que vai além do conhecimento metodológico, didático, do conteúdo.

E qual é a importância dos idiomas na educação básica? Rajagopalan (2003, p. 65) assevera que o interesse em aprender outras línguas consiste muitas vezes no desejo de "acesso a um mundo melhor", porque se quer "subir na vida". Contudo, defende que a importância reside na construção identitária do aprendiz: 
As línguas são a própria expressão das identidades de quem delas se apropria. Logo, quem transita entre diversos idiomas está redefinindo sua própria identidade. Dito de outra forma, quem aprende uma língua nova está se redefinindo como uma nova pessoa. (RAJAGOPALAN, 2003, p. 69).

As afirmações de Souza (2019, p. 304) coadunam com as expostas anteriormente: "O que move $90 \%$ dos pais para quererem que as crianças aprendam inglês é o mercado de trabalho e o vestibular. Querem instrumentalizar a criança desde o dia do nascimento para o mercado de trabalho." Entretanto, Souza (2019) aponta um aspecto fundamental das línguas "é criar esse senso crítico da sensibilidade linguística. Aprender a apreciar a lidar com as diferenças" (SOUZA, 2019, p. 304). Dessa forma, nesse contato com as diferenças, com o outro, o estudante pode refletir sobre sua própria língua e cultura, o que permite ressignificar seus saberes.

\section{A REFORMA DO ENSINO MÉDIO}

Há muito tempo, pesquisadores, gestores e professores debatem sobre a dicotomia entre a formação voltada para o trabalho e a preparação para o curso superior, nos anos finais da educação básica. Para Kuenzer (2002), temos basicamente dois desafios para a etapa do ensino médio: (a) sua democratização, que vai além de ampliação de vagas, requer também organização de espaços físicos adequados e atuação de profissionais habilitados e concursados; e (b) uma articulação entre o acadêmico e o profissional, na tentativa de superar a dicotomia histórica da formação voltada para o trabalho e da preparatória para o ensino superior.

Além dessa dicotomia, o Ministério da Educação (MEC) apresentou dados da pesquisa realizada, em 2016, pelo Índice Brasileiro de Opinião Pública e Estatística (Ibope), que mostrou alguns problemas do ensino médio ${ }^{5}$, por exemplo: (a) a escola é desinteressante e poucos alunos conseguem aprender o necessário; (b) o Índice de Desenvolvimento da Educação Básica (Ideb) está estagnado há mais de dez anos; (c) 70\% dos jovens não sabem o suficiente em matemática e português ao final desse segmento; (d) $41 \%$ dos alunos abandonam a escola antes de concluir essa etapa.

\footnotetext{
${ }^{5}$ Disponível em: <http://novoensinomedio.mec.gov.br/\#!/pagina-inicial>. Acesso em: 02 nov. 2019.
} 
Diante dos problemas mencionados por Kuenzer (2002) e dos elencados pelo MEC, surgiu a proposta da Reforma do Ensino Médio que, conforme mencionamos, foi apresentada como MP. O problema é que o caminho indicado pela Reforma retoma a divisão de um percurso profissionalizante para a classe trabalhadora e outro, acadêmico, para a elite. Kuenzer (2002, p. 29) afirma que, no período de criação de escolas técnicas, em 1942, tínhamos a dualidade, um caminho "para os que serão preparados para exercer suas funções de dirigentes; outro, para os que, com poucos anos de escolaridade, serão preparados para o mundo do trabalho em cursos específicos de formação profissional [...]" Com a Reforma o "novo" Ensino Médio, essa dualidade educacional é repetida e identificada na divisão dos currículos em itinerários, pois, de um lado, é resgatada a instrução profissional direcionada à formação de mão de obra, para a classe trabalhadora, e, de outro, teremos uma educação apontada como acesso ao ensino superior, que remete ao atendimento da elite. Kuenzer (2002, p. 39) assevera que "Para a maioria dos jovens, o exercício de um trabalho digno será a única possibilidade de continuar seus estudos em nível superior" e justamente por isso, o ensino médio deveria atender às duas necessidades: trabalho e ensino superior. Entretanto, a ideia de criar uma articulação entre o acadêmico e o profissional, mencionada por Kuenzer (2002), ficou ainda mais distante, porque aconteceu o inverso, explicitou-se o distanciamento.

Posteriormente, a MP foi transformada no Projeto de Lei (PL) no 34 (BRASIL, 2016b) que, após a votação e aprovação pelo Congresso Nacional, foi convertida na Lei $\mathrm{n}^{\circ}$ 13.415/2017, sancionada e, às pressas, promulgada pelo presidente da República. Todo esse trâmite ocorreu sem a participação efetiva de professores, especialistas, gestores ou da sociedade civil, isto é, o documento foi recebido pela comunidade educacional de forma hierárquica, arbitrária, obrigatória e de caráter normativo.

Na sequência, analisamos dois itens da Lei no 13.415/2017, quais sejam: itinerário formativo e o notório saber.

\section{Os itinerários formativos}

A Lei $n^{\circ} 13.415 / 2017$, em seu artigo $4^{\circ}$, afirma que o artigo 36 da Lei $n^{\circ}$ 9.394/1996, passa a vigorar com as seguintes alterações: 
Art. 36. O currículo do ensino médio será composto pela Base Nacional Comum Curricular e por itinerários formativos, que deverão ser organizados por meio da oferta de diferentes arranjos curriculares, conforme a relevância para o contexto local e a possibilidade dos sistemas de ensino, a saber:

I - linguagens e suas tecnologias;

II - matemática e suas tecnologias;

III - ciências da natureza e suas tecnologias;

IV - ciências humanas e sociais aplicadas;

$\mathrm{V}$ - formação técnica e profissional.

(BRASIL, 2017)

Conforme indica o artigo 36 transcrito, o currículo do ensino médio terá uma formação comum referente à BNCC (BRASIL, 2018b) e outra parte relacionada aos itinerários formativos. Dentre as justificativas para a necessidade da Reforma do Ensino Médio, em 2016, o então ministro da Educação mencionou ${ }^{6}$ : "Atualmente o ensino médio possui um currículo extenso, superficial e fragmentado, que não dialoga com a juventude, com o setor produtivo, tampouco com as demandas do século XXI.” Julgamos importante evidenciar que a existência dos itinerários continua propondo uma formação segmentada. Se por um lado as disciplinas passam a ser organizadas por áreas/itinerários, por outro, cada aluno vai escolher um percurso específico. Logo, a formação não será ampla, ao contrário, será limitada de acordo com o itinerário “escolhido". É importante prever que, em alguns casos, o estudante não conseguirá desenvolver o que realmente deseja estudar, uma vez que sua definição dependerá das opções ofertadas pela escola. Além disso, teremos outro complicador, considerando que o estudante terá que começar a escolher a área para seguir no ensino superior a partir do início do ensino médio. Ainda sobre o artigo 36, o que fica explicitado é o diálogo entre o setor produtivo, apresentado nas justificativas para a Reforma, e o itinerário V - formação técnica e profissional. Nesse sentido, apontamos indicações das perspectivas neoliberais quando ressaltam que procuram aliar o currículo ao setor produtivo, buscando formar mão de obra voltada para o crescimento econômico.

Ainda a respeito dos itinerários, a Resolução $n^{0} 3$, de 21 de novembro de 2018 (BRASIL, 2018a) esclarece que:

(a) os currículos do ensino médio são compostos por formação geral básica, que

\footnotetext{
${ }^{6}$ Disponível em: <http://www.planalto.gov.br/ccivil_03/_Ato2015-2018/2016/Exm/Exm-MP-746-16.pdf >. Acesso em: 3 mar. 2020.
} 
incluem as competências e as habilidades de todas as áreas indicadas na BNCC (BRASIL, $2018 \mathrm{~b})^{7}$, e pelos itinerários formativos (conforme Art. $6^{\circ}$, inciso II);

(b) Língua Portuguesa e Matemática devem ser incorporados durante todo o ensino médio (conforme Art. 11, $\S 7^{\circ}$ );

(c) especificamente para o itinerário de linguagens e suas tecnologias, estão previstos no Art. 12, inciso I:

aprofundamento de conhecimentos estruturantes para aplicação de diferentes linguagens em contextos sociais e de trabalho, estruturando arranjos curriculares que permitam estudos em línguas vernáculas, estrangeiras, clássicas e indígenas, Língua Brasileira de Sinais (LIBRAS), das artes, design, linguagens digitais, corporeidade, artes cênicas, roteiros, produções literárias, dentre outros, considerando o contexto local e as possibilidades de oferta pelos sistemas de ensino (BRASIL, 2018a).

A exposição desses incisos explicitados nas novas DCNEM (BRASIL, 2018a), reforçam a limitação e a fragmentação do currículo. Com relação às disciplinas de Língua Portuguesa e Matemática, Ferretti (2018) aponta que o fato de ser componentes obrigatórios durante todo o ensino médio tem caráter instrumental, já que interferem diretamente na aprendizagem de outras. Também é preciso evidenciar que o domínio dessas duas áreas, além dos conhecimentos da disciplina de Ciências, é comumente avaliado em exames internacionais como o Pisa (Programme for International Student Assessment). Dessa forma, notamos traços de políticas neoliberais voltados para meta e resultados em provas de larga escala.

No caso das línguas estrangeiras, o inglês e, como possibilidade de segunda oferta, o espanhol aparecem somente na formação geral básica. Além disso, seguirá com a aprendizagem de línguas adicionais apenas aquele que optar pelo itinerário I. A esse respeito, julgamos conveniente retomar a afirmação de que a escola não tem obrigatoriedade de ofertar todos os percursos formativos, ela o fará mediante suas possibilidades, portanto, ainda que o estudante se interesse por este itinerário, não significa que poderá segui-lo, uma vez que sua escolha é limitada mediante ao que será disponibilizado, segundo já mencionamos.

\footnotetext{
7 Áreas: I - linguagens e suas tecnologias; II - matemática e suas tecnologias; III - ciências da natureza e suas tecnologias; IV - ciências humanas e sociais aplicadas.
} 
Rajagopalan (2003) explica que o indivíduo que sabe uma língua estrangeira geralmente é visto com notoriedade, atitude justificada pela crença de que o domínio de outro idioma contribui para a melhoria de condições de vida. Contudo, existem diferenças nas percepções de prestígio de uma língua para outra: "quando a língua é considerada de menor prestígio, é quase sempre qualificada como 'exótica' ou até mesmo como um 'dialeto', e não como uma 'língua' propriamente dita” (RAJAGOPALAN, 2003, p. 65). Vale ressaltar que o privilégio para o inglês em todo território nacional evidencia o colonialismo presente em ideias neoliberais. Segundo já apresentamos, Jordão (2008) assevera que o colonialismo também se verifica quando o idioma, a cultura de um país se sobressai sobre outros, nesse caso, o inglês sobre outras línguas. Conforme mencionamos, antes havia a possibilidade de a comunidade escolher o ensino de outros idiomas considerando o contexto local e, nas DCNEM (BRASIL, 2018a), parágrafo $4^{\circ}$, inciso IX, passa a figurar que devem ser contemplados estudos e práticas de "língua inglesa, podendo ser oferecidas outras línguas estrangeiras, em caráter optativo, preferencialmente o espanhol, de acordo com a disponibilidade da instituição ou rede de ensino". Dessa forma, há possibilidades de ensino de outro idioma, somente em caráter optativo, e a língua adicional obrigatória, no currículo, está determinada que é o inglês, logo há uma língua que é mais importante que outras. Essa valorização da língua inglesa em detrimento de outras, de acordo com Jordão (2004) se dá porque, no mundo globalizado, ela foi transformada numa commodity que representa poder e prestígio e há a crença de que para conseguir prosperar economicamente ou socialmente, é preciso dominar esse idioma. Essa afirmação fica evidenciada, dentro do contexto neoliberal, quando para atender às necessidades de negociação, usa-se como língua oficial global.

Para Szundy (2019, p. 140), além de negar às comunidades a possibilidade de definir a língua estrangeira a ser ensinada, essa alteração na LDB, "ignora as práticas de uso das línguas(gens) de muitas regiões de fronteira, onde o domínio do espanhol desempenha papeis fundamentais nas (inter)ações locais." Diante da aprovação da Lei 13.415/2017, cabe evidenciar o movimento de professores de espanhol. O mote “\#FicaEspanhol”, iniciado no Rio Grande do Sul, a partir de ações do Programa Institucional de Bolsas de Iniciação a Docência (Pibid) da Universidade Federal do Rio Grande do Sul (UFRGS), conseguiu organizar-se, articular contatos, protocolar e aprovar 
a Proposta de Emenda Constitucional (PEC) que garante, desde dezembro de 2018, a oferta obrigatória do espanhol no ensino fundamental e médio das escolas públicas, na Constituição do Estado do Rio Grande do Sul. O movimento foi fortalecido, ganhou o país e, até agosto de 2020, havia representantes de quase todos os estados brasileiros e do distrito federal ${ }^{8}$. Há páginas nas redes sociais como Facebook $^{9}$ e Instagram $^{10}$, além de perfis específicos da organização de cada estado, envolvendo associações de professores de espanhol, alunos de cursos de graduação, professores das redes municipal, estadual e federal. O objetivo do coletivo é o fortalecimento das discussões e ações em prol da legitimação da disciplina de língua espanhola na legislação local e nos referenciais curriculares estadual e municipal.

Quanto à organização dos itinerários, as DCNEM (BRASIL, 2018a) explicam que:

(d) o ensino médio pode se organizar em semestres, "ciclos, módulos, sistemas de créditos, alternância regular de períodos de estudos, grupos não seriados com base na idade, na competência e em outros critérios" (conforme Art. 17, § $1^{\circ}$ );

(e) o ensino médio diurno deve ser desenvolvido em três anos, com carga horária total de 2.400 horas, chegando a 3.000 horas até o início de $2022^{11}$ (conforme Art. 17, § $\left.2^{\mathrm{o}}\right)$

(f) a formação geral básica deve ter, no máximo, 1.800 horas (conforme Art. 11, § $3^{\circ}$ ) e os itinerários formativos, portanto, 1.200 horas;

(g) a formação geral básica pode ser oferecida durante uma parte do ensino médio ou estar presente ao longo dos três anos, concomitante aos itinerários formativos (conforme Art. 11, $\S 7^{\circ}$ ).

Observamos uma total flexibilização quanto à forma de organizar os itinerários,

8 Conforme informações presentes no perfil \#FicaEspanhol do Instagram: $<$ https://www.instagram.com/p/CDkfNitnp3c/>. Acesso em: 14 ago. 2020.

9 Perfil \#FicaEspanhol no Facebook: <https://www.facebook.com/ficaespanhol/>. Acesso em: 14 ago. 2020.

${ }^{10}$ Perfil \#FicaEspanhol no Instagram: <https://www.instagram.com/fica.espanhol/>. Acesso em: 14 ago. 2020.

${ }^{11}$ A progressão da carga horária para o ensino médio deve atingir as 3.000 horas indicadas até o ano letivo de 2022. As DCNEM - Resolução n 3 (BRASIL, 2018a) também trazem especificações relacionadas ao ensino noturno com a possibilidade de aumento de tempo para cumprir o ensino médio; para a educação de jovens e adultos (EJA) apresentam indicações como realizar uma parte a distância e a há também esclarecimentos sobre a educação especial, educação do campo, educação escolar indígena, educação escolar quilombola, educação de pessoas em regime de acolhimento ou internação e em regime de privação de liberdade ou em cumprimento de medidas socioeducativas, educação escolar para pessoas em situação de itinerância e educação a distância. Considerando a necessidade de delimitação das discussões, neste trabalho, nos atemos às orientações para o ensino médio regular presentes no documento mencionado. 
seja com relação ao formato (semestralização, módulos, créditos, etc.), seja com relação à organização da carga horária de cada itinerário. Convém evidenciar que essas alternativas para o estudante construir sua formação podem ser um dificultador no caso de ele querer alterar o itinerário ou ter de mudar de escola. Sobre essa possibilidade ou necessidade de alterações no percurso, o documento indica que:

(h) o aluno pode alterar a escolha do itinerário desde que a instituição oferte o percurso de seu novo interesse e que se respeite suas normas específicas (ver Art. 12, § 12);

(i) os sistemas de ensino devem garantir mais de um itinerário em cada município (Art. 12, § $6^{\circ}$ );

(j) caso o estudante não consiga continuar o itinerário formativo por uma opção ou necessidade de alteração de escola, município ou estado, o documento indica que se proceda à reorientação do percurso por meio de aproveitamento de carga horária cursada. (Art. 12, § 13).

No item (h), a condição para que uma mudança no percurso se concretize é a instituição ofertar o itinerário do interesse do aluno, mas, conforme mencionamos, a escola não tem a obrigação de desenvolver todas as opções. Vale enfatizar que, provavelmente, as escolas particulares ofertarão maior quantidade de itinerários, com mais recursos e ferramentas para aprendizagem que as públicas, pois dentro do contexto neoliberal, há a valorização do privado e o entendimento que os serviços estatais são ineficientes e improdutivos.

No que se refere ao item (i), é indicado que os sistemas de ensino devem garantir a oferta de mais de um itinerário em cada município e não necessariamente todos os cinco percursos. Há que se considerar que algumas cidades têm apenas uma escola de ensino médio. Se não houver a possibilidade de ofertar todos os itinerários, o aluno pode ficar impedido de cursar o que realmente gostaria de estudar. Em situações de grandes centros urbanos, mesmo que as instituições ofereçam mais de um itinerário, isso pode ocorrer em escolas cuja distância inviabilize a opção. É importante ressaltar que em algumas propagandas do MEC, veiculadas nos meios de comunicação ${ }^{12}$, houve ênfase nessa

\footnotetext{
${ }^{12}$ Há pelo menos dois vídeos do MEC intitulado que enfatizam essa possibilidade de escolha dos itinerários formativos: (1) "Com o Novo Ensino Médio, você tem mais liberdade para escolher o que estudar!". Disponível em: <https://www.youtube.com/watch?v=kdERkLO3eTs $>$. Acesso em: 15 ago. 2020. (2) "O
} 
possibilidade de escolha, mas temos um engodo, pois, conforme mencionamos, a escola não está obrigada a ofertar todos os itinerários formativos, mesmo que seja a única instituição de ensino do município. Assim, ao levarmos em consideração as ideologias neoliberais, os itinerários voltados para a formação técnica e profissional serão mais desenvolvidos, pois o currículo escolar será estruturado de maneira que atenda às necessidades mercadológicas para o desenvolvimento da economia.

No item (j), por mais que se considere a carga horária cursada de um itinerário, é preciso levar em conta que diante de um novo percurso formativo, o que se cumpriu pode não constituir um conhecimento prévio necessário para dar continuidade ao novo projeto. Tal situação, para os neoliberais, não será considerada um fator dificultador, uma vez que serão enaltecidas as ações práticas direcionadas ao treinamento do indivíduo para alcançar resultados palpáveis, estimulando, assim, a individualidade e a competitividade. Nessa formação aligeirada, que pode ser fragmentada e desconectada, constituída por parte de carga horária de uma trilha, parte de outras, notamos a concepção de educação "bancária", criticada por Freire (1987), quando o aluno, que nada sabe, apenas recebe os "depósitos" do professor, detentor do conhecimento. Esses “depósitos” compartimentados e limitados não contribuem para a compreensão da totalidade da realidade. A função do aluno é, portanto, receber e reproduzir conhecimentos que não necessariamente fazem sentido em sua vida, é saber executar uma ação enquanto força trabalhadora, é manter o status quo da sociedade opressora e excludente.

Outras marcas neoliberais também podem ser constatadas em:

(k) os itinerários são organizados em torno de um ou mais eixos: I - investigação científica; II - processos criativos; III - mediação e intervenção sociocultural; IV empreendedorismo (Art. 12, $\S 2^{\circ}$, incisos I, II, III e IV);

(1) Para garantir a oferta de diferentes itinerários formativos, podem ser estabelecidas parcerias entre diferentes instituições de ensino, desde que sejam previamente credenciadas pelos sistemas de ensino, podendo os órgãos normativos em conjunto atuarem como harmonizador dos critérios para credenciamento (Art. 12, § $9^{\circ}$ ).

No item (k), cabe evidenciar que o termo empreendedorismo é bastante comum no

Novo Ensino Médio vai deixar o aprendizado mais estimulante e compatível com a sua realidade!". Disponível em: <https://www.youtube.com/watch?v=7_Fdhibi0yQ>. Acesso em: 15 ago. 2020. 
âmbito empresarial, compreendido como prática de ação inovadora para a solução de situações-problema. O Guia de implantação do novo ensino médio (BRASIL, 2018c) define como "a mobilização de conhecimentos de diferentes áreas para a formação de organizações com variadas missões voltadas ao desenvolvimento de produtos ou prestação de serviços inovadores com o uso das tecnologias." Segundo Souza (2012, p. 86), a defesa do empreendedorismo na educação (básica e ou superior) parte do pressuposto de que a cultura empreendedora trará melhoria no desenvolvimento econômico. Dessa forma, relacionamos a educação aos fins do mercado. Medeiros e Pires (2014) e Nascimento (2018) asseveram que, na perspectiva capitalista, o objetivo é alinhar parte dos alunos ao mercado de trabalho. Em contraposição, Freire (2010, p. 14) tece críticas à "malvadez neoliberal" e entende que "formar é muito mais do que puramente treinar o educando no desempenho de destrezas", assim, entendemos que formar é incentivar a criticidade e estimular novas maneiras de buscar conhecimento.

No item (1), abre-se o caminho para a parceria com o setor privado para atender a oferta dos diferentes itinerários. Conforme Costa e Coutinho (2018), essa relação entre público e privado é um caminho para isentar o estado de realizar investimentos em recursos humanos e infraestrutura para atender às novas propostas. Certamente as parcerias se darão com o setor privado interessado na mão de obra e, mais uma vez, notamos os pressupostos neoliberais para a educação atender ao mercado. Desse modo, conforme explicitado na Reforma, o Estado se considera desobrigado de oferecer diferentes opções dos itinerários formativos e, como possíveis consequências, temos o fortalecimento do setor privado e o aumento da quantidade de trabalhadores sem ou com pouco senso crítico.

Como afirma Szundy (2019, p. 125), “o neoliberalismo constrói o indivíduo como empreendedor de si, ou seja, um ser racional responsável por suas escolhas e fracassos". Quando se coloca o aluno como empreendedor de si mesmo, no que se refere à escolha do itinerário formativo, quando vemos a combinação de termos como competência, empreendedorismo e possibilidade de articulação com o setor privado, visualizamos tendências neoliberais no que se refere ao individualismo em detrimento do coletivo, a preparação para o mercado, em detrimento de uma formação humana e científica, além do enfraquecimento do setor público. Esse tipo de formação, com base na reforma curricular 
proposta que favorece o controle por meio de aplicação de provas em larga escala, a competitividade, a responsabilização e a meritocracia, contribui para o agravamento de problemas como a exclusão e as desigualdades sociais (FERRETTI, 2018).

\section{O notório saber}

Para ministrar aulas na educação básica, a Lei n ${ }^{\circ}$ 9.394/1996, no caput do Art. 62, articula que o corpo docente deve possuir, minimamente, curso de licenciatura. Entretanto, a Lei $n^{\circ}$ 13.415/2017, em seu Art. $6^{\circ}$ altera o Art. 61, inciso IV, da Lei $n^{\circ}$ 9.394/1996), passa a autorizar que profissionais sem licenciatura possam dar aulas, no ensino médio, especificamente no itinerário $\mathrm{V}$, ou seja, na formação técnica e profissional:

IV - Indivíduos com notório saber reconhecido pelos respectivos sistemas de ensino, para ministrar conteúdos de áreas afins à sua formação ou experiência profissional, atestados por titulação específica ou prática de ensino em unidades educacionais da rede pública ou privada ou das corporações privadas em que tenham atuado, exclusivamente para atender ao inciso $\mathrm{V}$ do caput do art. 36. (BRASIL, 2017).

A respeito desse aspecto, as novas DCNEM (BRASIL, 2018a) reforçam que essa regra vale especificamente para o itinerário de formação técnica e profissional. $O$ parágrafo único do Art. 29 indica que:

A docência nas instituições e redes de ensino que ofertam o itinerário de formação técnica e profissional poderá ser realizada por profissionais com comprovada competência técnica referente ao saber operativo de atividades inerentes à respectiva formação técnica e profissional. (BRASIL, 2018a).

Conforme o parágrafo único citado, para atuar no itinerário $\mathrm{V}$ é preciso ter comprovada competência técnica sem exigir nenhum tipo de graduação. Vale ressaltar que estamos considerando a atuação do professor na educação básica e esse tipo de flexibilidade certamente representa uma desvalorização da profissionalização docente. Evidencia-se, portanto, a concepção do Estado de que não é necessário passar por uma formação adequada e específica para atuar como professor. Há o desprezo aos variados 
esforços da classe, tais como o desenvolvimento de pesquisas sobre a temática, as discussões propostas em eventos acadêmicos, as políticas sobre formação de professores implantadas anteriormente, enfim, desconsideram-se as reivindicações para garantir que o exercício do magistério requeira formação específica, mesmo que seja como uma complementação pedagógica para os docentes desse itinerário.

Embora, por enquanto, o notório saber seja específico para atender à formação técnica e profissional, questionamos, desde já, os impactos e efeitos na formação docente e, consequentemente, na qualidade da educação brasileira, uma vez que a medida pode abrir precedentes para atender, por exemplo, a falta de professores em outras áreas. Conforme considera a Associação Nacional pela Formação dos Profissionais da Educação (ANFOPE), a iniciativa do notório saber além de desvalorizar a formação dos profissionais da educação, pode provocar a "desqualificação e desprofissionalização dos professores, impactando negativamente a qualidade do ensino e, consequentemente, a formação, a carreira e os salários do magistério" (ANFOPE, 2016).

Além disso, essa desvalorização da profissionalização evidencia a concepção de docência pautada na vocação e na reprodução de conteúdos produzidos por outros (OLIVEIRA; OLIVEIRA; ARAÚJO, 2017) e que não exige uma formação específica, crítica e reflexiva para atuar em sala de aula. Conforme Medeiros e Pires (2014, p. 43), "no sistema capital, não se espera do trabalhador a sua criação, reflexão sobre sua ação, objetivação de seu desenvolvimento intelectual e de suas potencialidades".

Em síntese, notamos que a atividade docente é compreendida como técnica para reproduzir conhecimentos para alunos concebidos como se tivessem conhecimentos homogêneos, em escola padronizada e conforme currículo padronizado. Na perspectiva conteudista, espera-se que o docente deposite a matéria e que o aprendiz receba esse depósito, segundo a educação bancária descrita e criticada por Freire (1987).

No caso do ensino de inglês, Sorte (2015) explica que alguns cursos de idiomas admitem pessoas sem formação específica para atuarem como professores, ou seja, sem licenciatura em Letras.

Com a multiplicação de cursos de idiomas e a possibilidade de assumir aulas de inglês por meio de contratos temporários em escolas públicas e privadas/, antes mesmo de concluir (ou iniciar) os cursos de graduação, 
alunos de Letras e também de outros cursos (Direito, Psicologia ou Administração, por exemplo) encontram, nesses empregos, algumas possibilidades: complementar a renda, fazer "bico", ocupar-se como professor ou aprender a profissão no sentido mais amplo, adquirindo experiência e inserindo-se no mercado de trabalho. Em cursos de idiomas, basta, muitas vezes, ter um inglês "fluente" e ministrar uma aula "legal" para se obter a vaga. Já em escolas regulares, públicas ou privadas, em muitos casos, é necessário estar, pelo menos, matriculado em um curso de licenciatura em Letras. (SORTE, 2015, p. 539).

O fragmento descrito por Sorte (2015) confirma que, em muitos casos, a docência é subentendida como capacitação técnica, como "treinamento", o professor é reconhecido como reprodutor de metodologias. Essa concepção opõe-se aos esforços em torno de uma formação crítica e reflexiva que propõe pensar, discutir sobre a própria prática, considerando o contexto de atuação, os alunos, as necessidades, os recursos disponíveis, o que é possível e pertinente desenvolver (SOUZA, 2019). Conforme Oliveira, Oliveira e Araújo (2017, p. 81), é preciso considerar a subjetividade do professor, "um sujeito que está inserido no mundo e que, a partir dele, cria suas concepções, sendo transformado constantemente, pois não está no mundo, mas também age nele e participa dele ativamente enquanto ator dotado de razão e personalidade própria".

Considerando esses dados e os pressupostos neoliberais, julgamos que o notório saber pode constituir-se em precedente para a entrada de profissionais não licenciados atuarem na educação básica como professores de idiomas. Recuperamos pesquisadores que tratam da importância da formação do professor como Monte Mór (2015) e Tardif (2014), por exemplo, que defendem que o educador não é mero reprodutor de técnicas, que esse profissional deve saber agir conforme suas bases teóricas e o reconhecimento de seu contexto. Especificamente no caso da profissionalização dos professores de línguas, para Monte Mór (2015, p. 38), "A reconceituação linguística, cultural, social, de construção de sentidos e de conhecimentos, de agência e crítica revela-se um conhecimento primordial [...]". O governo federal, na contramão, apresenta normas autoritárias, sem consulta pública, instituindo a permissividade para a docência e desvalorizando a formação do professor.

A quem essa política educacional atende? Segundo Ferretti (2018), a categoria empresarial nacional tem exercido forte influência no MEC, procurando alinhar a educação a seus interesses. Essa relação entre o governo e o grupo empresarial consolida- 
se, segundo o pesquisador, via construção de escolas, consultorias, enfim, com o estabelecimento de parcerias que exercem influências no currículo escolar, no material didático, nas avaliações em larga escala. Dessa forma, fica evidente que as mudanças devem atender ao mercado.

\section{CONSIDERAÇÕES FINAIS}

Neste estudo, apresentamos a análise de dois aspectos indicados na Lei $\mathrm{n}^{\circ}$ 13.415/2017, amparada pelo referencial teórico. Problematizamos questões referentes aos itinerários formativos e ao notório saber e discutimos as marcas neoliberais na educação, no desenvolvimento dos anos finais da educação básica e na desvalorização da formação docente para essa etapa de ensino.

As questões trazidas à tona mostram que o poder estatal estrutura as escolas de educação básica, públicas e privadas, num currículo padrão nacional para servir aos interesses do mercado de trabalho e, consequentemente, ao fortalecimento de políticas neoliberais.

Além disso, a Reforma colocou o aluno como empreendedor de si, ou seja, quando ele "escolhe" qual itinerário vai cursar, assume a responsabilidade pelo seu (in)sucesso escolar e profissional. Com isso, o Estado alega que ao tomar essas medidas, o ensino médio será mais atrativo e procura mitigar os problemas relacionados a essa etapa de ensino (baixos resultados em provas de larga escala, evasão e abandono escolar, reprovação, entre outros) como se a causa dos problemas se resumisse à organização curricular. Ferretti (2018) anuncia outros aspectos que precisam ser levados em conta, quais sejam, a infraestrutura física inadequada de várias escolas, a precarização do trabalho docente, além de questões sociais como a necessidade de o jovem ter que trabalhar para contribuir com a renda familiar, a gravidez na adolescência, a violência etc. Outros pesquisadores como Costa e Coutinho (2018), Rajagopalan (2019) analisam igualmente que a reforma curricular não é garantia de melhoria na educação pública.

Também evidenciamos que essa "escolha" do aluno pode ser uma falácia, já que os itinerários serão oferecidos conforme sua relevância local e possibilidades da escola. Quem determinará a relevância de determinado itinerário para a comunidade? Empresas locais? Julgamos importante salientar que as necessidades observadas na comunidade 
podem não coincidir com os interesses econômicos. Uma escola alinhada ao mercado pode almejar que o indivíduo seja capaz de executar apenas determinada função. Como consequência, teremos a educação bancária, o estudante recebe o conteúdo e o reproduz mecânica e passivamente. Para Medeiros e Pires (2014, p. 43), "A mecanização não propicia tempo e nem possibilita a intervenção de seu executor, dispensa-se investimentos intelectual e criativo, acentuando a separação entre pensamento e ação (...)". Assim, verificamos que medidas como a Reforma do Ensino Médio também servem para obedecer às imposições do neoliberalismo, ao direcionar as escolas para atender às demandas de mercado e, de preferência, sem nenhum aparato crítico.

Ademais, ao adotar ações paliativas que permitem o exercício do magistério, na educação básica, por profissionais sem formação específica, ainda que essa prerrogativa esteja restrita, inicialmente, para o ensino técnico e profissional, o Estado evidencia o quão desvalorizados estão os cursos de licenciatura, uma vez que tal norma refere-se à atuação na educação básica. Conforme mencionamos, pode abrir precedentes para que, na falta de professores para outros itinerários, também se possa recorrer ao notório saber. Assim, para lecionar, os indivíduos precisam apenas dominar conteúdo, sem uma formação específica para a docência, o que contraria as ideias dos estudos mencionados sobre a formação desse profissional (MONTE MÓR, 2015; TARDIF, 2014), conforme expusemos, na fundamentação teórica.

Em síntese, interpretamos a Reforma como um retrocesso aos encaminhamentos de uma educação mais ampla, libertadora e de valorização da profissionalização docente. $\mathrm{O}$ governo se "desresponsabiliza" da formação de professores sem apresentar uma política de formação inicial e continuada, de valorização da classe e "resolve" a falta de professores para esse segmento abrindo as portas para atuação de profissionais de outras áreas como se o magistério fosse apenas um "serviço extra".

\section{REFERÊNCIAS}

ANDRADE, D. P. O que é o neoliberalismo? A renovação do debate nas ciências sociais. Sociedade e Estado, v.34, p.211-239, 2019. Disponível em: $<$ https://www.scielo.br/scielo.php?script=sci_arttext\&pid=S0102-69922019000100211 >. Acesso em: 14 ago. 2020. 
ANFOPE. Associação Nacional pela Formação dos Profissionais da Educação. Manifesto contra a medida provisória $n^{o}$. 746/2016. Goiânia, 2016. Disponível em: $<$ http://www.anfope.org.br/wp-content/uploads/2018/05/Manifesto-Anfope-MP-74612.10.2016R.pdf>. Acesso em: 15 mar. 2020.

BONFANTE, J. G. C.; BETT, M. B. B.; BITTENCOURT, R. L. de. Contribuições de Giroux, Tardif e Contreras para pensar a formação de professores. Revista Internacional de formação de Professores. v.3, n.3, jul./set., p.79-93, 2018. Disponível em: $<$ https://periodicos.itp.ifsp.edu.br/index.php/RIFP/article/view/1317/1007>. Acesso em: 02 dez. 2019.

BRASIL. Base Nacional Comum Curricular. Ministério da Educação, Brasília, DF: MEC, 2018b. Disponível

em: $<$ http://basenacionalcomum.mec.gov.br/images/BNCC_EI_EF_110518_versaofinal_site.p df>. Acesso em: 26 out. 2020.

BRASIL. Emenda Constitucional $n^{o}$ 32, de 11 de setembro de 2001. Disponível em: $<$ http://www.planalto.gov.br/ccivil_03/constituicao/Emendas/Emc/emc32.htm>. Acesso em: 01 nov. 2019.

BRASIL. Guia de implementação do novo ensino médio. Brasília: MEC/Consed, 2018c. Disponível em: <http://novoensinomedio.mec.gov.br/resources/downloads/pdf/Guia.pdf>. Acesso em: 30 abr. 2020.

BRASIL. Lei $n^{\circ}$ 9.394, de 20 de dezembro de 1996. Lei de Diretrizes e Bases da Educação Nacional. Disponível em: <http://www.planalto.gov.br/ccivil_03/leis/L9394.htm>. Acesso em: 11 out. 2019.

BRASIL. Lei $n^{o} 11.161$, de 5 de agosto de 2005. Lei sobre o Ensino da Língua Espanhola. Disponível em: $\quad<$ http://www.planalto.gov.br/ccivil_03/_Ato20042006/2005/Lei/L11161.htm>. Acesso em: 15 mar. 2020.

BRASIL. Lei $n^{o} 11.494$, de 20 de junho de 2007. Lei sobre o Fundo de Manutenção e Desenvolvimento da Educação Básica e de Valorização dos Profissionais da Educação FUNDEB. Disponível em: <http://www.planalto.gov.br/ccivil_03/_ato20072010/2007/lei/l11494.htm>. Acesso em: 15 mar. 2020.

BRASIL. Lei $n^{o}$ 13.415, de 16 de fevereiro de 2017. Disponível em: $<$ http://www.planalto.gov.br/ccivil_03/_Ato2015-2018/2017/Lei/L13415.htm>. Acesso em: 11 out. 2019.

BRASIL. Medida Provisória $n^{o}$ 746, de 22 de setembro de 2016a. Disponível em: $<$ http://www.planalto.gov.br/ccivil_03/_Ato2015-2018/2016/Mpv/mpv746.htm $>$. Acesso em: 11 out. 2019.

BRASIL. Parâmetros Curriculares Nacionais. $3^{\circ}$ e $4^{\circ}$ Ciclos do Ensino Fundamental: língua estrangeira. Brasília: MEC/SEF, 1998. 
BRASIL. Projeto de Lei $n^{o}$ 34/2016, de 30 de novembro de 2016b. Disponível em: $<$ https://www.camara.leg.br/proposicoesWeb/fichadetramitacao?idProposicao=2119066\& ord=0>. Acesso em: 15 mar. 2020.

BRASIL. Resolução $n^{o}$ 3, de 21 de novembro de 2018a, que atualiza as Diretrizes Curriculares Nacionais para o Ensino Médio (DCNEM). Disponível em: $<$ http://pesquisa.in.gov.br/imprensa/jsp/visualiza/index.jsp?data $=22 / 11 / 2018 \&$ jornal $=515$

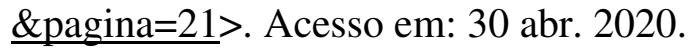

COSTA, M. A.; COUTINHO, E. H. L. Educação Profissional e a Reforma do Ensino Médio: lei no 13.415/2017. Educ. Real., Porto Alegre, v.43, n.4, p.1633-1652, out., 2018 . Disponível em: <http://www.scielo.br/scielo.php?script=sci_arttext\&pid=S217562362018000401633\&lng=en\&nrm=iso $>$. Acesso em: 30 abr. 2020.

FERRETTI, C. J. A reforma do Ensino Médio e sua questionável concepção de qualidade da educação. Estud. av., São Paulo, v.32, n.93, ago., p.25-42, 2018. Disponível em: $<$ http://www.scielo.br/scielo.php?script=sci_arttext\&pid=S0103-

40142018000200025\&lng=en\&nrm=iso $>$. Acesso em: 30 abr. 2020.

FREIRE, P. Pedagogia do oprimido. Rio de Janeiro: Paz e Terra, 1987.

FREIRE, P. Pedagogia da autonomia. São Paulo: Paz e Terra, 2010.

HARVEY, D. A brief history of neoliberalism. Oxford: Oxford University Press, 2005.

JORDÃO, C. M. A língua inglesa como 'commodity': direito ou dever de todos?. In: ROMANOWSKY, J. P.; MARTINS, P. L. O.; JUNQUEIRA, S. R. A. (Org.). Conhecimento Local e Conhecimento Universal. Curitiba: Champagnat, v.3, p.287-296, 2004.

JORDÃO, C. M. A Postcolonial Framework for Brazilian EFL Teachers' Social Identities. Matices en Lenguas Extranjeras, v.2, 2008. Disponível em: $<$ https://revistas.unal.edu.co/index.php/male/article/view/10702/2809>. Acesso em: 14 fev. 2020.

KUENZER, A. Z. (Org.). Ensino médio: construindo uma proposta para os que vivem do trabalho. 3. ed. São Paulo: Cortez, 2002.

LUDWIG, A. C. W. Conservadorismo e progressismo na formação docente. São Paulo: Pontes, 2000.

MEDEIROS, J. L.; PIRES, L. L. de A. Formação de Professores no Contexto das Políticas Neoliberais: Descaminhos Para A Formação Unitária. Anais da Semana de Licenciatura, Jataí, GO, p.38-50, mar., 2014. Disponível em: $<$ http://revistas.ifg.edu.br/semlic/article/view/466 > Acesso em: 05 nov. 2019. 
MONTE MÓR, W. A Profissionalização do Professor de Línguas Estrangeiras e o Projeto Educacional. In: TONELLI, J. R. A.; BRUNO, F. A. T. C. (Orgs.). Ensino-Aprendizagem de Inglês e Espanhol no Brasil: Práticas, Desafios e Perspectivas. Coleção NPLA, volume 43, p. 21-41, 2015.

NASCIMENTO, A. K. de O. Neoliberalismo e Língua Inglesa: um estudo de caso por meio do Pibid. Ilha do Desterro, v.71, p.39-58, 2018. Disponível em: <https://periodicos.ufsc.br/index.php/desterro/article/view/2175-8026.2018v71n3p39>.

Acesso em: 22 out. 2019.

OLIVEIRA, S. M. S. de; OLIVEIRA, A. I. B. de; ARAÚJO, F. M. L. Saberes, formação, profissionalização ou "notório saber": o que é preciso para ser professor? Revista Expressão Católica, v.6, n.1, jan./jun., p.78-84, 2017. Disponível em: $<$ http://publicacoesacademicas.unicatolicaquixada.edu.br/index.php/rec/article/view/2158/ pdf>. Acesso em: 22 out. 2019.

RAJAGOPALAN, K. Por uma linguística crítica: linguagem, identidade e a questão ética. São Paulo: Parábola Editorial, 2003.

RAJAGOPALAN, K. Reforma curricular e ensino. In: GERHARDT, A. F. L. M.; AMORIM, M. A. de (Orgs.). A BNCC e o ensino de línguas e literaturas. Campinas, SP: Pontes Editores, p. 23-39, 2019.

RODGERS, C. R. 'A transformação da alma' - Aprendendo a ensinar para a justiça social: o programa de formação de professores da Escola Putney (1950-1964). In: DINIZPEREIRA, J. E.; ZEICHNER, K. M. (Org.). Justiça Social: desafio para a formação de professores. Trad. Cristina Antunes. Belo Horizonte: Autêntica Editora, p. 35-73, 2008.

SORTE, P. B. Por que a graduação em Letras-Inglês pode ter o status de formação contínua? Rev. bras. linguist. apl., Belo Horizonte, v.15, n.3, p.537-564, set., 2015. Disponível em: $\quad$ http://www.scielo.br/scielo.php?script=sci_arttext\&pid=S198463982015000300537\&lng=en\&nrm=iso $>$. Acesso em: 30 abr. 2020.

SOUZA, L. M. T. M. de. Educação linguística: repensando os conceitos de língua e linguagem. In: FERRAZ, D. de M.; KAWACHI-FURLAN, C. J. (Orgs.). Bate-papo com educadores linguísticos: letramentos, formação docente e criticidade. São Paulo: Pimenta Cultural, p. 291-306, 2019.

SOUZA, S. A. de. A introdução do empreendedorismo na educação brasileira: primeiras considerações. Educação \& Linguagem, v. 15, n. 26, p. 77-94. jul./dez., p.77-94, 2012. Disponível em: <https://www.metodista.br/revistas/revistasims/index.php/EL/article/view/3291/3149>. Acesso em: 30 abr. 2020.

SZUNDY, P. T. C. A Base Nacional Comum Curricular e a lógica neoliberal: que línguas(gens) são (des)ligitimadas? In: GERHARDT, A. F. L. M.; AMORIM, M. A. de (Orgs.). A BNCC e o ensino de línguas e literaturas. Campinas, SP: Pontes Editores, p.121-151, 2019. 
TARDIF, M. Saberes docentes e formação profissional. 17. ed. Petrópolis, RJ: Vozes, 2014.

Recebido em: 30 abr. 2020.

Aceito em: 05 out. 2020. 